\title{
Bowl Dosing Unit
}

National Cancer Institute

\section{Source}

National Cancer Institute. Bowl Dosing Unit. NCI Thesaurus. Code C151970.

A dosing unit equal to the amount of smokable material in a pipe bowl. 